Euskal ikerketen aldizkaria | Revue d'études basques |

Revista de estudios vascos | Basque studies review

$20 \mid 2017$

Numéro $X X$

\title{
Bertso iraingarri eta ziri-kopla zaharrak Nafarroa
}

Garaian

\section{Urtzi Reguero Ugarte}

\section{OpenEdition}

\section{Journals}

Édition électronique

URL : https://journals.openedition.org/lapurdum/3574

DOI : 10.4000/lapurdum.3574

ISSN : 1965-0655

Éditeur

IKER

Édition imprimée

Date de publication : 1 janvier 2017

Pagination : 259-269

ISBN : 978-2-95534-135-3

ISSN : $1273-3830$

Référence électronique

Urtzi Reguero Ugarte, «Bertso iraingarri eta ziri-kopla zaharrak Nafarroa Garaian», Lapurdum [Linean], 20 | 2017, Sarean emana----an 01 janvier 2021, kontsultatu 03 septembre 2021. URL: http:// journals.openedition.org/lapurdum/3574 ; DOI: https://doi.org/10.4000/lapurdum.3574 


\title{
Bertso iraingarri eta ziri-kopla zaharrak Nafarroa Garaian
}

\author{
Urtzi REGUERO UGARTE \\ UPV/EHU - Aziti Bihia
}

\section{Sarrera ${ }^{1 *}$}

Ahozko literaturak, ahozko izateagatik beragatik, halabeharrez, galtzeko, aldatzeko eta moldatzeko joera handiagoa du idatzizkoak baino. Horregatik, denboran zenbat eta atzerago joan, orduan eta zailagoa da ahozko literaturaren aztarnarik eta lekukotasun idatzirik aurkitzea; are gehiago euskara bezalako literatura idatzi urriko hizkuntza batean. Testigantzarik ez egoteak ez du adierazten, ordea, ahozko literatura urria izan denik euskaraz; aitzitik, Mitxelenak (1960: 86) esan bezala, "la literatura popular vasca, esencialmente oral, es probablemente tan rica y tan variada como la de cualquier otro pueblo".

Hango eta hemengo artxibategi eta liburutegietako agiri zaharretan xerka ariturik, bada antzinagoko garaietako ahozko literatur tradizioaz ezer esan lezaketen lekukotasunik; hauetan bada XVI, XVII eta XVIII. mendeetan euskarazko ahozko herri literatura profanoaren aztarnarik. Badira ahozkotasunetik gertu leudeken errefrau bildumak, Refranes y sentencias berak edota Isasti, Garibai, Bela, Oihenart eta Zalgizeren bildumek erakuts lezaketenez. Baina, hauezaz landara, badira bertsoak, koplak edo kantuak ere ahozkorako sortu eta ondoren idatziz jaso zirenak.

Hori dela eta, Xarles Bidegainen omenezko lan honetan ekarpen xume gisa, XVI, XVII eta xVIII. mendeetan lekukoturik gelditu diren hiru bertso dakartzagu. Gehiago zehaztuz, hona dakartzagunak ziri-bertsoak dira, inoiz inork inor zirikatzeko, irrigarri uzteko eta iraintzeko

1. "Lan hau Euskal Herriko Unibertsitateak (UPV/EHU) 2010/2011 ikasturtean lau urtetarako emandako Ikertzaileen prestakuntzarako laguntzari esker burutu ahal izan da (kodea: PIF10/2010/ PIF10017). Halaber, UFI11/14 erreferentziadun UPV/EHUko formazio eta ikerketa taldearen eta MINECOk finantzatutako "Monumenta Linguae Vasconum (IV): textos arcaicos vascos y euskera antiguo" (kodea: FFI2012-37696) proiektuaren baitan egina da gure lana. Eskerrak eman behar dizkiot Ricardo Gómezi honen aurrenko bertsioari egindako iruzkin eta oharrengatik. 
idatziak. Lehena Etxalekukoa da xv. mende akabuan sortu, baina idatziz hurrengo mendearen erdialdean jaso zena. Bertan Martitxo Musu delako bat iraintzen da. Bigarrena 1600 urtean sortu zen Imarkoainen bera baino askozaz gazteagoa zen batekin ezkondu zen gizon bati kantatzeko. Azkena Zubietan sortu zen xviII. mendearen bigarren erdialdean. Antza denez Juan Bautista Garbisok kantatu eta kantarazi zituen On Tomas delako bati jarritako bertso hauek, honen emazteak atezainarekin zuen harreman "ezkutukoagatik".

\section{Ahozko zein idatzizko bertso zaharrak goi-nafarreraz}

Atutxak (2011: 171) "filologiaren azken helburua herri edo historia garai bat(zu)en ezagutza eta berreraikuntza osoa" dela dio, "bere(n) hizkuntza, literatura eta kultur emaitza ororen azterketaren bitartez". Esan gabe doa, beraz, euskal filologoon egitekoetako bat dela paper zaharren artean diren euskarazko kultur adierazpenak bildu eta behar bezala finkatzea, hauetan oinarriturik kultur ezagutzan sakontzeko.

Beste kultura ugaritan bezala, kantua da eta izan da, zeinahi delarik ere gaia, kultur adierazpideetarik bat euskaldunen artean. Madariagak (2014: 523) halaxe azaltzen du:

(1) "Es proverbial el gusto de los vascos por las composiciones rimadas, improvisadas o no, cantadas o recitadas, cultas o populares, de temas religiosos o profanos, escritas o conservadas por tradición oral... Podría decirse que el verso ha contribuido decididamente al uso, cultivo y mantenimiento de la lengua".

Ohitura aspaldikoa dela dirudi, bai behintzat xv. mendeaz geroztikoa; ordukoak baitira, besteak beste, lekukotzen diren euskaraz kantatutako lehen eresiak eta baladak. Nafarroa Garaiari dagokionez, ez da bertsogintza zaharraren tradiziotik lekora gelditu; urriak izan arren, badira inprobisatuak edo idatziak, kultuak edo herrikoiak, erlijiozkoak edo profanoak diren bertso zaharrak. Honako lan honen helburua goi-nafarrerazko hiru bertso zahar zirikatzaile aurkeztea bada ere, ahozko literatur mota hau ezin uler genezake besterik gabe. Gisa honetako kantuak sortzea tradizio zabalago baten parte da, zalantzarik gabe. Garai zaharrenetako lekukotasunak urriak dira, baina bada bertso zaharren lekukotasunik gurean.

Inoiz kantatutzat har dezakegun lekukotasun orain artean zaharrena 1493koa da, nahiz eta idatziz xviII. mende hastapenetan jaso zuen Alesonek, Moretek abiatutako Annales del reino de Navarra (1684-1715) lanean; kasu honetan, Nafarroako kondestableari kantatu zitzaion. Halaxe dakar Alesonek: ${ }^{2}$

(2) "En uno de estos interludios ó entremeses se cantó esta copla en vascuence, segun refiere el autor de las memorias manuscritas.

2. 1891ko edizioa baliatu dugu hona ekartzeko; hain zuzen ere, XXXV. liburuko IV. kapituluan agertzen da, 131. orrialdean. 


$\begin{array}{ll}\text { Labrit etá Erregué } & \text { Labrit padre y Rey hijo } \\ \text { aytá semé diráde, } & \text { si quereis acertarlo, } \\ \text { condestable jauna } & \text { al señor condestable } \\ \text { ar bizate anáie. } & \text { Tomadle por hermano." }\end{array}$

Beranduxeago, sormenerako gaitasun eta ohituraren erakusle izan liteke Juan Amenduxek 1564an idatzitako bertsoa (TAV 3.1.8); ez dakigu inon kantatzeko sortua izan ote zen, baina bakarra izan arren, konposizioak berak iradoki dezake halakoak idazteko joera, edo sortzekoa bederen, bazela orduko Nafarroan. Hamarkada bat lehenago, 1554an, Henrike Borboikoaren jaiotza dela-eta inork sortu zuen bertsorik (Haritschellar 1983); ez dakigu ziur, ordea, inoiz kantatu ote zen ala soilik idatziz jaso. Haritschellarrek dakarren faksimilean oinarriturik dakargu ondokoa:

(3) "Gure Principe don Henrrique Iaunari.
Mundu gucia hona vetor, aur noble onengana, oin escuen apazcera, iaun andiari beçala.
Ez iaio da, ez iaioco yor onen ygoala hanvat vada seynale andi ceruan dacusaguna.
Lenguoaíe oroc vadiote varon handia çarala nìc diosçut cyratela iaun gucien iáuna."

XVII. mendean olerki kultu eta jantzien artean ditugu 1609ko Corpus egunean Iruñean saritutako Ezkurra, Aldaz eta Elizalderen hiru olerkiak. Garai bertsukoa da, halaber, Juan Huarteren 1619ko Historia de Orreaga liburu eskuizkribatuan ertz batean gehitu zuen Orreagako amari eskainitako bertsoa (TAV 3.1.24). Hurrengo mendean, 1731n argitaratu zuen El origen y antigüedad de la lengua bascongada y de la nobleza de Cantabria liburuan Perotxegik ondoko bertsoa jaso zuen kristau kaparetasunaren gorazarre: ${ }^{3}$

3. 1731ko argitalpeneko aldaera da hona dakarguna, baina 1738 eta 1760ko argitalpenetan ere bertso bera jasotzen da, aldaera grafikoak gorabera. 1760 argitalpenean "Difinicion sobre la essencia de la nobleza" izenburua eman zitzaion bertsoari. 


\author{
"Ohore handia da eguiazqui \\ aita nobletaric iaustea, \\ bainan urruntzen dira segurqui \\ diotenec hau dela asco yzatea. \\ Nior esta ceruan sartucò \\ es ohore onerat helducò \\ norc ere bere aldetic \\ es badu arcen prestutasunà \\ eta hidalguiaren edertasunà \\ Iesus estiaren amoriotic."
}

Idatziz jasotako bertso profanoen artean dugu Isastik 1626an jaso zuen Miguel Sueskunen zortzikoa (TAV 3.1.19). Aipagarri dira, halaber, 1666n Gure erregue Philippe Andiaren heriotzean euscarazco coplac (TAV 3.1.28) izenburupean argitaratu ziren hamar koplak ere.

Ez da gugana XVI edo xviI. mendeko Lazarragaren edo Etxepareren pareko olerkari oparo nafarrik iritsi, baina ziurrenik gugana heldu direnak baino kantu eta bertso gehiago baziren, inoiz idatzi ez zirenak edo hala jarri baziren galdurik daudenak. Dena dela, adibide nahiko baditugu pentsatzeko bazela bertsorako eta koplatarako joera; urriak izan arren, lekukotasunak dira horren testigu. Beraz, gatozen harira. Eman ditugun adibideak lan honen aurre hitzak besterik ez ziren, gaia ziri-bertsoak baitira.

\title{
3. Ziri-bertso zaharrak Nafarroa Garaian XVI, XVII eta XVIII. mendeetan
}

Askotarikoak izan litezke bertsotarako gaiak, eta nonahi topa liteke sormena piztu dezakeen gairik. Dena dela, bada aurreko atalekoak bezalako egoera horietan kantatzen zirenez landara, beste testuinguru batean sortu eta kantatzen ziren bertso edo koplak ere: ziri-bertsoak, alegia. Bestearen gaitz edo kalteez barre egitea ez bide da kontu berria. xvi. menderako badira ziri-bertsoak kantatzen zirela aipatzen duten lekukotasunak; zeharkakoak zein zuzenekoak. Izan ere, kasurik gehienetan bertsoak edo koplak euskaraz kantatu zirela esan bai, baina kopla bera ez da jasotzen agirietan. Zeinahi izan zitekeen aitzakia: adar kontuak, adin desberdintasun handikoen arteko ezkontzak, nagusiek hitz emandako ezkontzak, etab.

Euskal Herri osoan sortzen ziren halako koplak, eta ongi errotutako ohitura zela dirudi; horren lekuko dugu, besteak beste, Madariagak (2014: 524) emandako adibidea. Bertan ikusten denez, 1452an formalizatutako Bizkaiko Foru zaharrean gogorki salatzen ziren gehienbat emakumeek kantatzen zituzten koplak eta eresiak. Eta hauxe da beste datu interesgarria: maiz emakumeak ziren kopla hauek kantatzen zituztenak.

Lekukotasunek diotenez, Nafarroa garaian oso ohikoa zen garai hartan ziri-bertsoak kantatzea besteen gaitzez trufatzeko. Honen adibide interesgarri andana Madariagak (2014: 527) jaso ditu; bertatik aterea da, esate baterako, 1613ko ondoko aipua:

(5) "(...) y un dia en particular, se ocupo [Sancho de Argañaraz] parte de aquel en casa de Mari Martin de Abarçuça, viuda, de donde vio que Maria de Liçasoain, muger de Juan Fernandez de Ariçaleta y Joana de Liçaberria, su criada, estubieron en el orno coziendo pan y bio que desde alli a vozes, la dicha Joana 
de Liçaberria, acusada, començo a deçir coplas en bascuençe, motejando a la dicha Maria Martin de Abarçuça, que se entendia con el quexante [el cura] y andaba tras el de rincon en rincon (...)"

Jarraian, Nafarroa Garaian lekukotutako hiru ziri-bertso dakartzagu, xVI, xVII eta xvIII. mendean lekukotuak. Agiri zaharretan xerka arituz gero, gehiago ager litezke, eta halaxe espero dugu, baina, gauden-gaudenean, hauek dira ezagutzen ditugun zaharrenak: lehena Etxalekun sortua, bigarrena Imarkoainen eta, azkena eta berriena, Zubietan. Hirurak dira zirikatzeko, iraintzeko edo inor desohoratzeko sortuak. Beraz, guk dakartzagun hiru hauek dagoeneko Urkizuk (2009) eta Kalzakortak (2010) aztertutakoei gehitu behar zaizkie. Gisa bereko bertso iraingarriak bide dira oraino argitaratu gabe dagoen 1799ko Irungo bertso elebiduna ${ }^{4}$ eta Asteasun agertutako 1816ko bertsoak.

\subsection{Etxalekuko bertsoa}

Euskaraz kantatutako kopla hau Imozko Etxalekun asmatutakoa da, eta Maria Iturburukoren bigarren senar Martitxo Musuri iseka egiteko sortu zen. Dirudienez, 1491n Maria Iturburukok bereak ziren Etxalekuko jauregia eta dorrea Uharte Arakilgo Filipe Beamonti saldu zizkion, eta alargundu ondoren, Martitxo Musu morroiarekin ezkondu zen. Eratsungo gizon batek auzitara eraman zuen Maria, jauregi eta dorrea bereak zirela esanez. Auziagatik, eta diru larritasunek hartaraturik, Maria Iturburukok jauregia eta dorrea saldu behar izan zituen, Martitxoren onespenarekin. Tratuaren arabera Maria Uhartek Arakilera aldatu behar zuen, Filiperekin bizitzera. Egoera horrek eraginda ondu zituen Etxalekuko jendeak testu honetako bertsoak.

Bide batez, kopla hau da Nafarroako gertakari bati erreferentzia egiten dion euskal bertsorik zaharrena, Alesonek jasotakoa baino bizpahiru urte lehenagokoa. Halaber, kopla agertzen den dokumentua ere euskal kantu bat jasotzen duen zaharrena litzateke; izan ere, ezagutzen diren hurrengo kantu zaharrak Garibairen lanetan eta Ibaguen-Cachopin kronikan beranduago jaso ziren.

Bertsoa 1541 eta 1546 bitartean idatzitako prozesu ${ }^{5}$ batean dago. Antza denez, 1491 inguruan jazo zen gertakaria (Urrizolak 2007: 61), baina testiguen adierazpenak 15411546 bitartean jaso bide ziren. Beraz, bertsoa ziurrenik 1491 inguruan sortu bazen ere, xvI. mendearen erdialdean bildutakoa da. Honela dator aipatu agirian bertsoaren aurretik:

(6) "(...) a cabo de pocos dias, bio este testigo al dicho don Filipe de Beamont en el dicho lugar de Echalecu en el dicho palacio y torre, y llebó a la dicha María de Yturrburua, según dezían, para la dicha villa de Huart de la bal de Araquil, y el dicho Marticho Mussu, su marido, se fue adonde pudo. Y, como assí se dixo

4. Bilbaok (2013 : 725) ematen du erreferentzia zehatza, Badator sisteman egindako bilaketaren emaitza.

5. Nafarroako Artxibo Nagusia, 197.511 zbkia. 13r fol. 
y se fue el dicho Marticho Mussu, llevantaron y pussieron una copla al dicho Marticho Mucho en bascoence, deziendo ansí"

Azalpenaren ondotik dator bertsoa:

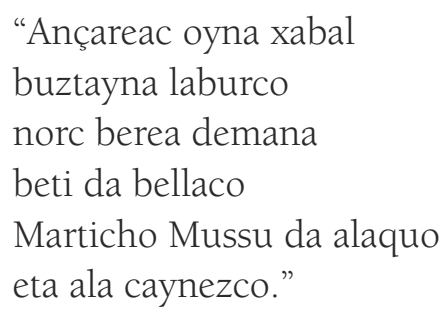

Egitura aldetik ezagutzen diren kopla zaharren tankera bertsukoa da: lehen begiratuan, aurreneko bi lerroek gutxi dute ikustekorik datozen hurrengoekin, eta naturako elementuak sartzen dira, kasu honetan antzarrak. Silaba eta errima aldetik, 6 lerro ditu, $7-6 a-7-6 a-$ $8 a-7 a$ egitura jarraitzen du.

\subsection{Imarkoaingo koplak}

Dakigula, Imarkoainen kantatu ziren kopla hauek, eta 1600 urteko prozesu batean ${ }^{6}$ jaso zen; eta Maiora Mendiak (2011 : 111) eman zuen ezagutzera lehen aldiz. Bertsio bera birritan lekukotzen da, lehena lekukoaren testigantza jasotzen denean eta bigarrena epaian edo amaierako laburpenean. Madariagak (2014: 528) laburbiltzen duenez, urte hartako San Martin bezperan eta egunean bertan kantatu zieten gazteek herritar alargundu adindu bati, bera baino gazteago batekin ezkondu berri zelako. Prozesuan esaten denez, zintzarri eta turutekin lagundurik kantatu zituzten euskarazko kopla imarkoaindar gazteek, hauen artean zen Martin Sanz delakoa:

(8) “(...) anduvieron en el dicho lugar, dando çençerrada, tañendo unos çençerros y una corneta de bidro (...) y oyo que el dicho Martin Sanz canto en basquenz lo siguiente:

Landan heder olaçe, begui duenac areçe liçençiaric paguindu coplaçera guendozque.

en una copla y luego en otra:

Ezpoz çara çu

bay acheguin baduçu

çeure andre galanta ori

6. Nafarroako Artxibo Nagusia, 296.389 zbkia. 24v eta 25v fol. 
ongui besarqueçaçu."

Agiri berean aurrerago joanda, bertso bera agertzen da aldaketa grafiko batzuk gorabehera:

(9) "Estando los dichos acusados en la dicha plaça comprendio que en dos coplas que canto el dicho Martin Sanz, acusado, dezia en la una en bascuenz:

Landan eder olaze

begui duenac areze

liçençiaripaguindu

coplazera guendozque

y en la otra

Ezpoz çara zu

bay acheguin baduzu

çeure andre galanta ori

ongui besarquezazu."

Honako bi kopla hauek launa lerro dituzte, eta lehen biek eta azkenengoak dute errima: a a - a. Bietarik lehenak, agi denez, ohiko egitura du: lehendabiziko bi lerroetan naturako elementuak agertzen dira konparaziorako (landa, aretze 'zekorra') eta azken bi lerroetan agertzen da mezua, alegia, kasu honetan, bistan da, koplak sortzeko konturen bat bada, baimenik ez ordea. Bigarrengo koplan, aldiz, mezua zuzenagoa da eta gertakariarekin lotua bide dago. Bertan aipatzen den Ezpoz da iraindua eta honekin ezkondu zuen Maria Sanestebanek bere inudea.

\subsection{Zubietako ziri-bertsoa}

Aurkeztuko dugun azken bertsoa Zubietan jarri zen 1781ean, ${ }^{7}$ eta Maiora Mendiak (2011: 174-177) eman zuen ezagutzera. ${ }^{8}$ Antza denez, Juan Bautista Garbiso Zubietako eskolako maisua izan zen bertso iraingarri hau kantatu eta besteei kantarazi ziena; prozesua, hain zuzen ere, bertsoan Joaquina Noguera eta On Thomas Jose Narbartekoa iraintzen direlako ireki zen.

Bertso hauek agiri horretan bi aldiz agertzen dira, baina bietan lerro guztiak tatxaturik daude, ziurrenik bertsoa kantatzea debekatu zutenez, inoren iraingarri gerta ez zedin eta inork

7. Nafarroako Artxibo Nagusia, 219093 zbkia, 4r, 138r eta 138v fol.

8. Gure irakurketak alde nabarmenak ditu Maiora Mendiarenarekin konparatuta; Madariagak (2014: 542) Maiora Mendiaren irakurketa bera dakar. 
prozesuko agiritik ikas ez zezan. Ondorioz, askotan zaila da jartzen duena irakurtzen. ${ }^{9}$

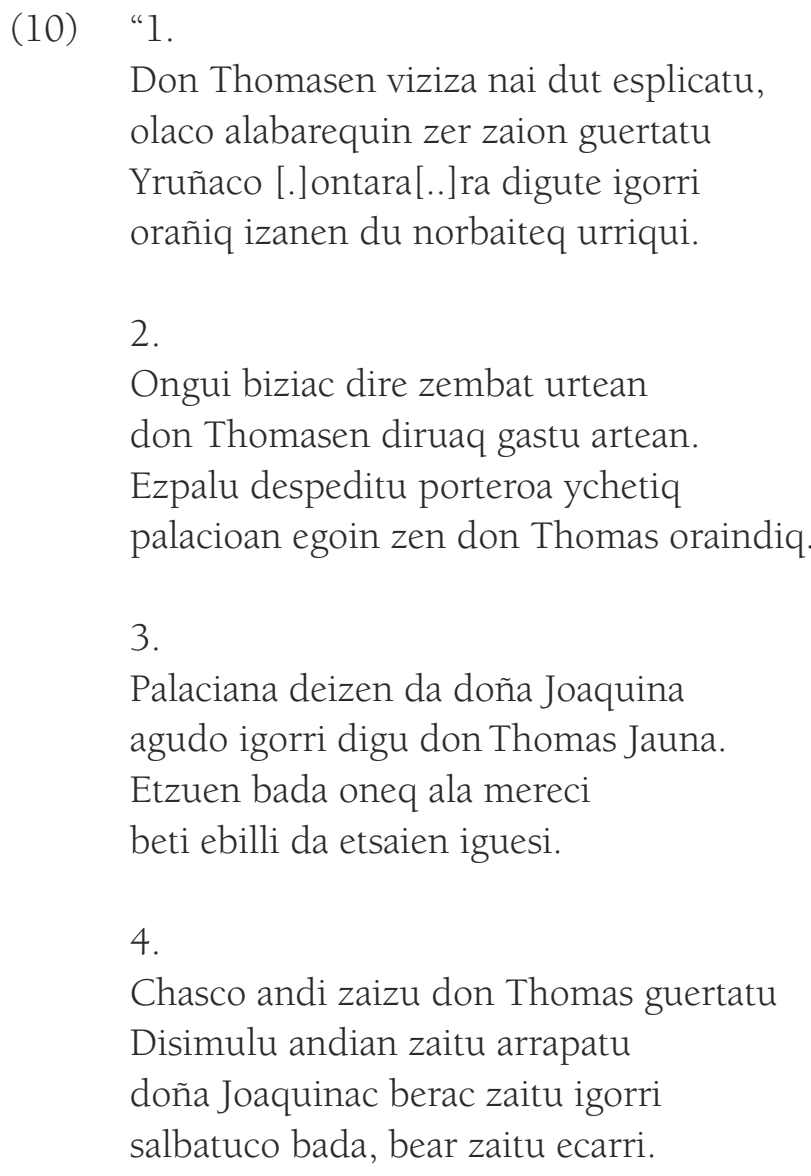

5.

Porteroa zagonean espensan gorderic ezuen oraiñ bezala salan paseazeco libertaderic, nagusiac ez naita echeco andreary deitu ondra andi batequin orai da guelditu.

6.

Palaciana egoten cen porteroarequin, elizara bidean disimularequin, elizaco atean gombersacioan yende gucia dago murmuracioan.

9. Bi aldaerak izan ditugu oinarri hemengo testua ontzeko, baina, bistan denez, pasarte askotan ez da testua ongi ulertzen. Hori dela eta, hizki bat falta dela argi dugunean [.] jarri dugu, bi falta direnetan [..] eta gehiago falta direnetan edo zenbat diren ez dakigunean [...]. 
7.

Yñon ezta pasatu onelaco conturiq:

don Thomas igorri dute bere ychetiq.

Don Thomas atera ta porteroa sartu

porteroaq bear omen du palacioan [...]tu.

8.

Yende gucia dago admiraturiq

señorac [...] du justiciariq

niq eztaquit bada cer duen pensacen

señora vizi cen porteroa maitacen

9.

Doña Joaquina eta bere alaba ere porteroarequin desconsolatuco dire

berbera juanen zaio laugarrentaco

don Thomasen diruac chocolatetaco.

10.

Señora Palaciana cer den pensacen

Yende gucieq zaitu gaur notazen

Garbo andiarequin duzu castigatu

porteroarequin zaizu sal[...] paseatu.

11.

Culpac dituztenac errian dirade

don Thomas ecarri eta igorri bear dute

ura igarri dutenec dute jaun[...]

bereala [...]ain ez sala[...]

12.

Alabaq erran dio bere aitari

zertaco ezpain zabalori

Certaco [...]d[.] erran [...] yduqui

orainiq vizi bearquo izarr[...] [...]qui.

13.

Yende guciac [...] Palaciana[...]

sei urteco alardeaq bear dutela oraitus.

Culpariq eztuena ezta aren beldur

yende guciac nai luque eguiten agur.

14.

Norbaiteq erranen du ori andrea salazera

don Thomas bear luquete ecarri bere ichera 
andreac culpac [...] castigatu

beguira daquien xaincoari damutu

15.

Berso au yzanen da amabosgarrena

orain gueldizea yzanen da onena

orieq zartu orduco berceac pasatuco

dietan guezurriq bada bear didazu barcatu."

Ikusi litekeenez, bertso hauek aurrekoak baino luzeagoak eta landuagoak dira; eta hobeto islatzen dute gertakaria bera. Egiturari dagokionez, hamabost ahapaldiak launa lerrokoak dira eta lehen biek eta azken biek egiten dute errima: AABB. Silaba kopuruari dagokionez, kontua ez dugu horren garbi.

\section{Azken hitza}

Lan honetan gaur arte aski ezagunak ez ziren hiru bertso iraingarri zahar eman ditugu; eta saiatu gara erakusten Nafarroa Garaian, oro har Euskal Herriko gainerako eremuetan bezala, kanturako eta bertsoak sortzeko ohitura errotua zegoela. Ez hori bakarrik, emandako adibideetan erakutsi dugu gutxienez xvIII. mendera arte pertsonaren duintasuna zipriztintzeko, zikintzeko eta iraintzeko sortutako bertsoak ugari zirela. Halaber, azpimarratu dugu eta erakusten saiatu Nafarroa Garaiko ahozko tradizioko kanturako eta bertsoak sortzeko ohitura tradizio zabalago batekin lotua dagoela.

Berriki Txema Hidalgok (2013) Nafarroan xv. mendeaz geroztik sortu diren kantuak bildu ditu bi liburuki ederretan. Orotara mende hartatik 1936an piztutako Gerra Zibil bitarterainoko 1.500 kantu bildu ditu; hona ekarri ditugunak bilduma osatzen lagun lezakete, eta, ziurrenik, gugana iritsi direnak baino gehiago izan litezke XVI, XVII eta XVIII. mendeetan, eta baita ondokoetan, sortu ziren olerki eta bertsoak.

\section{Erreferentziak}

Atutxa, Isaak. 2011. Testukritika eta euskal testuen edizioaz. In J. A. Lakarra, J. Gorrotxategi \& B. Urgell (arg.), 2nd Conference of the Luis Michelena Chair - Koldo Mitxelena Katedraren II. Biltzarra - II. Congreso de la Cátedra Luis Michelena, Vitoria - Gasteiz: UPV/EHU.

Bilbao, Gidor. 2013. Textos Arcaicos Vascos 50 urte geroago. In Ricardo Gómez, Joaquín Gorochategui, Joseba A. Lakarra \& Céline Mounole (arg), Koldo Mitxelena Katedraren III. Biltzarra. III. Congreso de la Cátedra Luis Michelena. $3^{\text {rd }}$ Conference of the Luis Michelena Chair. Bilbo: UPV/EHU.

Haritschelhar, Jean. 1983. Une poésie basque du milieu du xvième siècle célébrant la naissance de Henri III de Navarre (futur Henri IV). Iker 2. 259-274.

Hidalgo, Txema. 2013. Nafar aire zaharretan. 2 liburuki. Iruñea: Kapare.

Kalzakorta, Javier 2010. 1721. urteko Eibarko kopla zaharrak. Litterae vasconicae: euskeraren iker atalak 11, 9-33.

Lekuona, J. M., López de Luzuriaga J.I. \& Antxon Narbaiza. 1992. 1685eko kopla zaharrak, 
Ego Ibarra, Zarautz.

Lekuona, M. 1978. Literatura oral vasca (hirugarren edizioa), Kardaberaz bazkuna, Tolosa.

Madariaga Orbea, Juan. 2014. Sociedad y lengua vasca en los siglos XVII y XVIII. Euskaltzaindia, Bilbo.

Maiora Mendia, Fernando. 2011. Reino de Navarra. Euskera. Injurias, coplas, frases. Artaxona.

Mitxelena, Koldo. 1960. Historia de la literatura vasca. Madril: Minotauro. Bigarren arg. Donostia: Erein, 1988.

TAV: Mitxelena, Koldo. 1964. Textos Arcaicos Vascos, ASJUren gehigarriak 11, Donostia: Gipuzkoako Foru Aldundia.

Urkizu, Patri, 2009, Ziri-bertso eta eska-kopla argitaragabeak (1770, 1827). In Juan Mari Lekuonari omenaldia (Iker-23). Bilbo: Euskaltzaindia, , 429-443.

Urrizola, Ricardo. 2007. La copla de Etxaleku. FLV 104. 59-66. 